\title{
Monitoring the crude fat and cholesterol content and fatty acid composition of commercial ice cream products in Korea
}

\author{
So-Ra Sim, Ye-Seul Kim, Jeung-Hee Lee* \\ Department of Food and Nutrition, Daegu University, Gyeongsan 38453, Korea
}

\section{국내 유통 아이스크림 제품류의 조지방과 콜레스테롤 함량 및 지방산 조성 모니터링

$$
\begin{gathered}
\text { 심소라 - 김예슬 - 이정희* } \\
\text { 대구대학교 식품영양학과 }
\end{gathered}
$$

\begin{abstract}
Commercial ice cream products in Korea were categorized by type, and their crude fat and cholesterol content and fatty acid composition were analyzed and compared with the information from their packaging labels and nutritional facts. The crude fat and cholesterol contents were 7.00-12.49 w/w\% and 22.80-27.34 mg/100 $\mathrm{g}$ in regular ice creams, 6.27-11.02\% and $25.26-29.65 \mathrm{mg} / 100 \mathrm{~g}$ in franchised ice creams, $2.99-7.14 \%$ and $8.96-20.72 \mathrm{mg} / 100 \mathrm{~g}$ in ice milks, $5.43-6.03 \%$ and 0-2.41 mg/100g in non-fat ice creams, and 1.48-4.21\% and 3.70-5.76 mg/100 $\mathrm{g}$ in sherbet, respectively. The milk fat contents provided on the labels of two regular ice creams were lower than their analyzed crude fat contents. The cholesterol contents of four regular ice creams and five ice milks were higher than those provided in their nutritional facts. Most ice cream products contained approximately 2-4 times more saturated fatty acids than unsaturated fatty acids. The major fatty acids in regular and franchised ice creams and ice milks were palmitic, organic, myristic, and lauric acids, and along with small amounts of trans fatty acids. Regular ice creams and ice milks containing both milk fat and vegetable fat were high in lauric acid or palmitic acid. The analyzed cholesterol and crude fat contents were similar to or different from the information provided by the manufacturer. Therefore, it is necessary to periodically analyze and monitor the lipid profile of commercial ice creams.
\end{abstract}

Key words : ice cream, crude fat, fatty acid composition, cholesterol

서 론

아이스크림 제품은 전 세대가 좋아하는 간식으로 특히 여 름철 선호도가 높은 기호식품이다. 국내 아이스크림 시장은 2013년 1조 251억 원, 2015년 1조 1,070억 원, 2016년 1조 9,618억 원으로 지속적으로 증가하였지만, 저출산 시대의 도 래, 디저트 트랜드의 빠른 변화, 소비자들의 건강과 웰빙에 대한 관심의 증가로 인해 아이스크림 제품 시장은 2018년 1
조 6,291억 원으로 감소하는 경향을 보였다(AT FIS, 2019). 우리나라 식품공전의 '식품별 기준 및 규격'에 따르면 아이 스크림류는 제품에 함유된 유지방분과 유고형분의 함량에 따 라 ‘아이스크림'(유지방분 $6 \%$ 이상, 유고형분 $16 \%$ 이상), ‘아이스밀크'(유지방분 $2 \%$ 이상, 유고형분 $7 \%$ 이상), ‘저지 방 아이스크림'(무지유고형분 $10 \%$ 이상, 조지방 $2 \%$ 이하), ‘샤베트'(무지유고형분 $2 \%$ 이상), '비유지방 아이스크림'(무 지유고형분 $5 \%$ 이상, 조지방 $5 \%$ 이상)으로 분류된다(MFDS,

*Corresponding author. E-mail : jeunghlee@daegu.ac.kr, Phone : +82-53-850-6836, Fax : +82-53-850-6839

Received 28 May 2020; Revised 13 July 2020; Accepted 13 July 2020.

Copyright (c) The Korean Society of Food Preservation.

This is an Open Access article distributed under the terms of the Creative Commons Attribution Non-Commercial License (http://creativecommons.org/licenses/by-nc/4.0) which permits unrestricted non-commercial use, distribution, and reproduction in any medium, provided the original work is properly cited. 
2019). 미국 Food and Drug Administration은 아이스크림은 최소한 $10 \%$ 의 유지방과 $20 \%$ 의 유고형분을 함유하여야 한다고 규정하고 있다(Kilara와 Chandan, 2007).

아이스크림의 주된 지방 공급원인 유지방은 대부분 triacylglycerol(98-99\%)이고, 인지질(phospholipid), 스테롤(sterol), 지용성 비타민(A, D, E, K) 등으로 구성되며, 유지방구(milk fat globule)와 유지방구막(milk fat globule membrane)에 존 재한다(Han, 2005; Parodi, 2004). 유지방은 포화지방산(60$70 \%$, 단일불포화지방산 $(25-35 \%)$, 다가불포화지방산(4-5\%), 트랜스지방산(2-3\%)으로 구성된다(Han, 2005; Mansson, 2008). 주요 포화지방산은 palmitic, stearic, myristic acid이 고, 미량의 butyric, caproic, caprylic, capric acid를 포함하며, 주요 불포화지방산은 oleic과 linoleic acid로 구성된다(Han, 2005; Han, 2017). 유지방은 아이스크림 제품에서 독특한 풍 미와 부드러운 질감을 제공하고, 유지방 함량은 아이스크림 품 질에 영향을 준다. 야자유, 팜유 또는 팜핵유 등의 식물성유지 또한 아이스크림 제조에 이용되며(Clarke, 2015; Underdown 등, 2011), 이들 유지는 유지방의 지방산 조성과 유사하거나 포화지방산의 함량 $(89-90 \%)$ 이 많아, 아이스크림 조직을 유 지하고, 녹는 시간을 지연시키고, 풍부한 청량감과 저렴한 가 격으로 인해 자주 이용되지만, 부드러운 질감과 풍미가 감소 될 수 있다(Han, 2005; Smith, 2015; Underdown 등, 2011).

유지방의 스테롤 중 약 $95 \%$ 는 콜레스테롤이고, 주로 유지 방구막의 구성성분으로 존재한다(Parodi, 2004). 우유의 콜레 스테롤은 미량(약 $14 \mathrm{mg} / 100 \mathrm{~g})$ 이지만, 유제품으로 가공되면 농축되어 함량이 증가하여 버터는 $219 \mathrm{mg} / 100 \mathrm{~g}$, 크림(유지 방 $36 \%$ 함유)은 $137 \mathrm{mg} / 100 \mathrm{~g}$, 아이스크림(유지방 $15 \%$ 함 유)은 $68 \mathrm{mg} / 100 \mathrm{~g}$ 으로 된다(Han 등, 2006; Posati와 Orr, 1976). 특히, 아이스크림은 [고열량 - 저영양 식품]인 어린이 기호식품으로 식품의약품안전처(KFDA)에서 정한 기준보다 열량이 높고 영양가가 낮은 식품으로서 비만이나 영양 불균 형을 초래할 우려가 있는 식품으로 규정되고 있다(MFDS, 2019). 또한, 유지방의 포화지방과 콜레스테롤은 심혈관질환, 동맥경화증, 당뇨병, 암 및 기타 질병의 발병과 관련하여 부 정적인 영향을 미친다(Parodi, 2004).

국내 유통되는 프리미엄급 바닐라 아이스크림은 $12.7-13.5 \%$ 의 지방을 함유하고(Choi와 Shin, 2014), 미국 시장에서 유통 되는 바닐라 아이스크림의 지방함량은 $0.1-14.3 \%$ 로 제품에 따라 함량 차이가 매우 크다(Warren와 Hartel, 2014). Shin 등 (2006)은 국내 아이스크림을 식품공전별로 나누고, 지방함량 을 분석하여 일반 아이스크림은 $5-11 \%$, 프리미엄 아이스크 림은 $13-17 \%$, 아이스크림은 2-10\%로 보고하였고, 지방산 분 석을 통해 각 제품에 사용된 지방의 원재료를 조사하였다. Kolk 등(2007)은 에스토니안 아이스크림의 지방과 콜레스테
롤 함량은 각각 $5.9-12.54 \%$ 와 $16.3-32.8 \mathrm{mg} / 100 \mathrm{~g}$ 이고, 분석 된 지방함량은 포장지에 제공된 지방함량(4.73-13.64\%)과 차 이가 있으며 이는 아이스크림에 함유된 다양한 원료(과일, 잼, 시리얼, 향신료 등)의 첨가로 인한 것으로 보고하였다. 국 내 아이스크림 제품의 콜레스테롤 함량에 관한 연구결과는 없는 실정이며, 단지 시중 판매되는 유가공품 또는 가공식품 들 중에서 아이스크림의 콜레스테롤 함량을 분석한 결과(바 닐라 아이스크림, $28.77 \mathrm{mg} / 100 \mathrm{~g}$ )가 보고된 바 있으며, 시중 유통 아이스크림의 유형별 콜레스테롤 함량분석에 관해 연구 는 제한적이다(Duan 등, 2019).

아이스크림 제조사는 포장 라벨을 통해 소비자들에게 원 재료(예, 지방)의 종류와 함량, 1 회 제공량당 열량과 지방(포 화지방, 트랜스지방, 콜레스테롤)을 포함한 영양성분표를 제 공하고 있다. 반면, 프랜차이즈식으로 판매되는 프리미엄급 아이스크림은 가공식품이 아닌 조리식품으로 분류되어, 원재 료명과 첨가량에 대한 일괄표시가 어려워, 일반적으로 유통 되는 아이스크림과는 달리 성분표시가 미흡한 경우가 많다. 따라서 국내 유통되는 프리미엄급 아이스크림의 지방조성과 더불어 포장지 라벨에 제공된 지방의 종류 및 콜레스테롤 함 량이 정확히 표기되었는지 확인해볼 필요가 있다. 본 연구에 서는 시중 유통되는 아이스크림 제품을 구입하여 식품공전의 기준과 규격으로 분류한 후 유형별 조지방 함량, 지방산 조성 및 콜레스테롤 함량을 분석하고, 이들 분석결과와 제조사가 제공한 지방 profile에 부합되는지 모니터링하였다.

\section{재료 및 방법}

\section{실험재료 및 시약}

국내 시장에서 유통되는 일반 ‘아이스크림' 4 개 제품, ‘아 이스밀크' 9개 제품, '샤베트' 4개 제품, '비유지방 아이스크 림' 2개 제품, '빙과류' 2개 제품을 Lotte mart(Daegu, Korea) 에서 구입하여 시료로 사용하였다. 프랜차이즈 '아이스크림' 4개 제품은 아이스크림 전문점(Daegu, Korea)에서 구매하였 다. 본 연구에서는 식품공전상에 분류된 아이스크림을 일반 아이스크림과 프랜차이즈 아이스크림을 세분하여 분석을 실 시하였다. Ethanol, $n$-hexane, ethyl acetate, isooctane, heptane 는 Fisher Scientific International, Inc.(Hampton, NH, USA) 에서, butylated hydroxytoluene, ammonia $\left(\mathrm{NH}_{3}\right)$, boron trifluoride $\left(\mathrm{BF}_{3}\right)$ in methanol는 Samchun Pure Chemical Co., Ltd.(Seoul, Korea)에서 구입하였다. 콜레스테롤 유도체화를 위한 hexamethyldisilane과 trimethylchlorosilane은 SigmaAldrich Co., Ltd.(St. Louis, MO, USA)에서 구입하였다. 표 준물질인 cholesterol과 5 $\alpha$-cholestane은 Sigma-Aldrich Co., Ltd., triundecanoin은 NU-CHEK PREP, Inc.(Elysian, MN, 
USA), Supelco 37 Component FAME Mix는 Supelco Inc.(Bellefonte, PA, USA)에서 구입하였다.

\section{조지방 함량 측정}

아이스크림의 지방 추출은 Rose-Gottlieb법을 이용하였다 (MFDS, 2019). 아이스크림을 녹여 균질화시킨 후 시료 3 $\mathrm{g}( \pm 0.05)$ 을 마조니아관에 정량하고, 내부표준물질인 triundecanoin을 넣고, 증류수 $10 \mathrm{~mL}$ 와 ethanol $10 \mathrm{~mL}$ 를 첨가하여 water bath(C-WBE-DH, Changshin scientific Co., Seoul, Korea)에서 $40-50^{\circ} \mathrm{C}$ 로 가온한 후 충분히 vortex mixing한 다 음 ammonia $1.5 \mathrm{~mL}$ 를 가하였다. Dimethyl ether와 petroleum ether를 첨가하여 5 분간 진탕하고 원심분리 $(2,500 \times g, 10$ 분 $)$ 한 후 상층액을 sodium sulfate column에 통과시켜 수분을 제 거하고 농축시켜 항량이 될 때까지 무게를 측정하여 조지방 함량 $(\mathrm{w} / \mathrm{w} \%)$ 을 측정하였다.

\section{Gas chromatography에 의한 지방산 조성 분석}

추출한 조지방 $50 \mathrm{mg}$ 에 $0.5 \mathrm{~N}$ methanolic $\mathrm{NaOH}$ 용액(1.5 $\mathrm{mL})$ 첨가하고 water bath $\left(100^{\circ} \mathrm{C}\right)$ 에서 saponifcation하였다. 냉 각 후 $\mathrm{BF}_{3}$-methanol $2 \mathrm{~mL}$ 를 첨가하고, 다시 water bath $\left(100^{\circ} \mathrm{C}\right)$ 에서 methylation하였다. 냉각 후 isooctane $2 \mathrm{~mL}$ 를 넣고 혼 합하고, 포화 $\mathrm{NaCl} 1 \mathrm{~mL}$ 를 넣어 진탕한 후 원심분리(2,500 $\times g, 5 \mathrm{~min}$ ) 하여 상층액을 sodium sulfate column에 통과시 켜 수분을 제거하였다. 지방산 조성은 gas chromatography (GC-2010 Plus, Shimadzu Corp., Kyoto, Japan)를 이용하여 분석하였고, detector는 flame ionized detector(FID), column 은 $\mathrm{SP}^{\mathrm{TM}}-2560$ (bis cyanopropyl polysiloxane, $100 \mathrm{~m} \times 0.25$ $\mathrm{mm} \times 0.2 \mu \mathrm{m}$, Supelco Inc.)을 사용하였다. Injector와 detector 의 온도는 각각 $250^{\circ} \mathrm{C}$ 와 $260^{\circ} \mathrm{C}$, split ratio는 $100: 1$, column flow $\left(\mathrm{N}_{2}\right)$ 는 $1.00 \mathrm{~mL} / \mathrm{min}$ 으로 설정하였다. 오븐 온도는 초기 에 $100^{\circ} \mathrm{C}$ 에서 5 분간 유지한 다음 $240^{\circ} \mathrm{C}$ 까지 $4^{\circ} \mathrm{C} / \mathrm{min}$ 으로 승 온시켜 40 분간 유지하였다. $\mathrm{GC}$ 분석으로 얻은 시료 chromatogram과 standard chromatogram의 retention time을 비교 하여 각 지방산을 동정하고, 피크의 면적을 구하여 $\mathrm{area} \%$ 로 나타내었다.

\section{Gas chromatography에 의한 cholesterol 분석}

식품공전 일반시험법의 cholesterol 추출 방법을 참고하여 아이스크림에 함유된 cholesterol을 추출하였다(MFDS, 2019). 시료 $5 \mathrm{~g}( \pm 0.05)$ 을 추출관에 정량하여 $6 \%$ pyrogallol(in ethanol)을 넣어 2 분 동안 vortexing하고, 10 분 동안 sonication 하였다. $\mathrm{KOH}$ 용액 $(60 \%, 8 \mathrm{~mL})$ 를 가하여 2분 동안 vortexing하고, 추출관 내 공기를 $\mathrm{N}_{2}$ 로 치환한 후 shaking water bath(DAIHAN LabTech Co., Ltd., Namyangju, Korea)
에서 $75^{\circ} \mathrm{C}, 100 \mathrm{rpm}, 60$ 분에서 반응시킨 후 냉각하고, $2 \%$ $\mathrm{NaCl}(20 \mathrm{~mL})$ 를 혼합하였다. 추출 용매( $n$-hexane:ethyl acetate= $85: 15, \mathrm{v} / \mathrm{v}, 0.01 \% \mathrm{BHT}, 15 \mathrm{~mL}$ )를 첨가하여 2분 vortexing 한 후 상층액을 분리하여 sodium sulfate column 통과시킨 후 (3번 반복), $50 \mathrm{~mL}$ vial에 정용하였다.

추출액 $(12.5 \mathrm{~mL})$ 의 용매를 $\mathrm{N}_{2}$ 로 제거한 후 $3 \mathrm{~mL}$ dimethylformanide(DMF)에 재용해하고, cholesterol의 유도체화 를 위해 $2 \mathrm{~mL}$ hexamethyldisilane과 $0.1 \mathrm{~mL}$ trimethylchlorosilane을 넣어 혼합한 후 15 분간 정치하였다. 내부표준용액 ( $1 \mathrm{~mL}$ of $0.1 \mathrm{mg} / \mathrm{mL} 5 \alpha$-cholestane in heptane)과 증류수 10 $\mathrm{mL}$ 를 넣고 교반한 다음 원심분리 $(3,000 \times g, 2$ 분)하여 상등액 을 분리한 후 수분을 제거하였다. Cholesterol 정량분석은 GC-FID와 HP-ULTRA2 column(Agilent Technologies Inc, $25 \mathrm{~m} \times 0.32 \mathrm{~mm} \times 0.17 \mu \mathrm{m}$, Santa Clara, CA, USA)을 사용하 였다. Flow velocity는 $1 \mathrm{~mL} / \mathrm{min}$, carrier gas는 helium 사용 하였다. Injector와 detector의 온도는 각각 $250^{\circ} \mathrm{C}$ 와 $300^{\circ} \mathrm{C}$ 으로 설정하였다. 오븐 온도는 $190^{\circ} \mathrm{C}$ 에서 2 분간 유지, 2 $0^{\circ} \mathrm{C} / \mathrm{min}$ 으로 $230^{\circ} \mathrm{C}$ 까지 승온시켜 3 분간 유지, $40^{\circ} \mathrm{C} / \mathrm{min}$ 로 $255^{\circ} \mathrm{C}$ 까지 승온시켜 25 분간 유지하였다. Cholesterol 표준 용액을 유도체화하여 standard curve를 얻은 후, 시료의 cholesterol 함량을 $\mathrm{mg} / 100 \mathrm{~g}$ 아이스크림으로 나타내었다.

\section{통계처리}

아이스크림 제품의 조지방과 콜레스테롤 함량 및 지방산 조성 결과는 평균과 표준편차로 나타내었고, SAS 9.4 (Statistical Analysis System, SAS Institute Inc, Cary, NC, USA)을 사용하여 분산분석을 실시하고 Duncan's multiple range test를 이용하여 각 시료 간의 통계적 유의성을 $\mathrm{p}<0.05$ 수준에서 검정하였다.

\section{결과 및 고찰}

\section{아이스크림 유형별 조지방 함량}

시중 유통되는 아이스크림 조지방 함량 $(\mathrm{w} / \mathrm{w} \%)$ 은 일반 '아 이스크림' 7.00-12.49\%, 프랜차이즈 '아이스크림' $6.27-11.02 \%$, '아이스밀크' $2.99-7.14 \%$, ‘샤베트' $1.48-4.21 \%$ '비유지방 아 이스크림' $5.43-6.03 \%$, ‘빙과' $0.17-0.76 \%$ 으로 분석되었다 (Table 1). Shin 등(2006)이 보고한 일반 ‘아이스크림'(5-11\%), 프리미엄 '아이스크림'(13-17\%), '아이스밀크'(2-10\%), ‘샤 베트'(2-7\%), '비유지방 아이스크림’(4-11\%)의 지방함량과 유사하였다. 식품공전의 식품별 기준 및 규격에 따르면 아이 스크림과 아이스밀크는 조지방함량에 관한 기준은 없지만, 유지방을 각각 $6 \%$ 와 $2 \%$ 이상을 함유해야 하는데(MFDS, 2019), 일반 아이스크림과 아이스밀크의 포장 라벨에 제공된 
Table 1. Crude fat content analyzed and lipid information provided in package label of the commercial ice cream products

\begin{tabular}{|c|c|c|c|c|}
\hline \multirow[b]{2}{*}{ Type of products } & \multirow[b]{2}{*}{ No. } & \multirow{2}{*}{$\begin{array}{c}\text { Analyzed } \\
\text { Content of } \\
\text { crude fat }(w / w \%)\end{array}$} & \multicolumn{2}{|r|}{ Packaging label } \\
\hline & & & $\begin{array}{l}\text { Content of } \\
\text { milk fat }(w / v \%)\end{array}$ & Other fats / Remarks \\
\hline \multirow{4}{*}{$\begin{array}{c}\text { Regular } \\
\text { 'ice creams' }\end{array}$} & A1 & $12.49 \pm 0.79^{1 \mathrm{a} 2)}$ & $14 \%$ & $-3)$ \\
\hline & A2 & $7.00 \pm 0.37^{\mathrm{b}}$ & $10 \%$ & - \\
\hline & $\mathrm{A} 3$ & $7.59 \pm 0.17^{b}$ & $8 \%$ & - \\
\hline & A4 & $11.35 \pm 0.65^{\mathrm{a}}$ & $7 \%$ & $\begin{array}{l}\text { Processed butter chocolate (vegetable oil) cookie (shortening, } \\
\text { partially hydrogenated oils) }\end{array}$ \\
\hline \multirow{4}{*}{$\begin{array}{l}\text { Franchised } \\
\text { 'ice creams' }\end{array}$} & $\mathrm{B} 1$ & $6.27 \pm 0.10^{\mathrm{b}}$ & - & Green tea ice cream \\
\hline & B2 & $10.23 \pm 0.94^{\mathrm{a}}$ & - & Chocolate ice cream \\
\hline & B3 & $6.89 \pm 0.71^{\mathrm{b}}$ & - & Mellon ice cream \\
\hline & B4 & $11.02 \pm 0.86^{\mathrm{a}}$ & - & Mint chocolate chip ice cream \\
\hline \multirow{9}{*}{ 'Ice milks' } & $\mathrm{C} 1$ & $6.57 \pm 0.36^{\mathrm{a}}$ & $4 \%$ & Coconut oil, cookie (palm oil) \\
\hline & $\mathrm{C} 2$ & $2.99 \pm 0.53^{\mathrm{c}}$ & $4 \%$ & Processed butter \\
\hline & $\mathrm{C} 3$ & $6.06 \pm 0.32^{\mathrm{a}}$ & $5 \%$ & $\begin{array}{l}\text { Processed butter (cream, coconut oil) } \\
\text { coconut oil, vegetable oil }\end{array}$ \\
\hline & $\mathrm{C} 4$ & $6.18 \pm 0.38^{\mathrm{a}}$ & $6 \%$ & Processed butter (cream, coconut oil) \\
\hline & $\mathrm{C} 5$ & $3.76 \pm 0.88^{\mathrm{bc}}$ & $6 \%$ & - \\
\hline & C6 & $7.14 \pm 0.73^{\mathrm{a}}$ & $3 \%$ & Castela, cookie, coconut oil \\
\hline & $\mathrm{C} 7$ & $4.00 \pm 0.0^{\mathrm{bc}}$ & $2 \%$ & - \\
\hline & $\mathrm{C} 8$ & $3.87 \pm 0.34^{\mathrm{bc}}$ & $2 \%$ & - \\
\hline & C9 & $4.60 \pm 0.2^{\mathrm{b}}$ & $2 \%$ & - \\
\hline \multirow{4}{*}{ 'Sherbets' } & D1 & $3.23 \pm 0.09^{b}$ & - & Coconut oil \\
\hline & D2 & $1.48 \pm 0.50^{\mathrm{c}}$ & - & - \\
\hline & D3 & $2.43 \pm 0.28^{\mathrm{b}}$ & - & - \\
\hline & D4 & $4.21 \pm 0.3^{\mathrm{a}}$ & - & Coconut oil \\
\hline \multirow{2}{*}{$\begin{array}{l}\text { 'Nonfat ice } \\
\text { creams' }\end{array}$} & E1 & $5.43 \pm 0.55^{\mathrm{a}}$ & - & Palm oil \\
\hline & E2 & $6.03 \pm 0.17^{\mathrm{a}}$ & - & Cookie (palm oil), coconut oill \\
\hline \multirow{2}{*}{ 'Water ices' } & $\mathrm{F} 1$ & $0.17 \pm 0.0^{\mathrm{b}}$ & - & Coconut oil \\
\hline & $\mathrm{F} 2$ & $0.76 \pm 0.09^{\mathrm{a}}$ & - & Hydrogenated coconut oil \\
\hline
\end{tabular}

${ }^{1)}$ Mean \pm SD $(n=2)$.

${ }^{2)}$ Means in the same type of ice cream product with different letters are significantly different at $\mathrm{p}<0.05$ level.

${ }^{3)}$ Not available.

유지방 함량은 각각 $7-14 \%$ 와 2-6\%으로 표기되어 있어, 라벨 상으로 식품공전의 식품별 기준에 부합한 것으로 보인다 (Table 1). '비유지방 아이스크림'은 식품공전에서 조지방 $5 \%$ 이상을 규정하고 있는데, 본 연구에서는 5.43-6.03\%로 분석되어 지방함량이 적절한 것으로 보인다. '샤베트'에 대한
조지방 함량에 대한 규정은 없으며, '빙과'는 먹는 물에 식품 또는 식품첨가물을 혼합하여 냉동된 것으로 유가공품으로 해 당되지 않으며, 지방 함량에 대한 규정은 없다(MFDS, 2019). 아이스크림 제품들은 대형마트, 슈퍼마켓, 편의점 등에서 유 통되지만, 프랜차이즈 '아이스크림'은 아이스크림 전문점에 
서 판매되는데, 한국표준산업분류에서 기타 간이 음식점업으 로 분류되어 일반아이스크림 제품과 같은 성분표시와 유지방 함량의 제공에는 제한이 있다(KSIC, 2019). 국내에서 프랜차 이즈 형태로 판매되는 대부분의 아이스크림은 프리미엄급으 로 분류되며 일반 아이스크림에 비해 가격이 비싸고 유지방 함량이 높다. 유지방은 아이스크림의 풍미를 증가시키고, 부 드러운 조직감을 부여하고 입안을 매끄럽게 하는 장점이 있 으며, 첨가량은 국가별 기준(3-10\% 이상), 관능적 특성, 가격, 경쟁력 등에 의해 결정되며, 유지방 함량에 따라 economy (8-10\%), standard(10-12\%), premium(12-15\%), super premium ice cream(15-18\%)으로 분류된다(Goff와 Hartel, 2012). 국가 별 유지방 함량 기준을 살펴보면, 미국, 호주, 캐나다와 독일 은 $10 \%$, 이탈리아와 핀란드는 $8 \%$, 덴마크와 영국은 $5 \%$, 브 라질은 $3 \%$ 이상으로 정하고 있다(Goff와 Hartel, 2012).

일반 '아이스크림' A-1과 A-4의 조지방 함량은 A-2와 A-3 보다 유의적으로 높았다 $(\mathrm{p}<0.05)$. A-2에 표기된 유지방은 $10 \%$ 이지만, 조지방은 $7.00 \pm 0.37 \%$ 로 분석되어 차이가 있었 는데, 이는 분석결과를 표현하는 단위(제조사, $\mathrm{w} / \mathrm{v} \%$; 본 연 구, $\mathrm{w} / \mathrm{w} \%)$ 의 상이함 또는 라벨에 제공된 유지방 함량보다 낮은 첨가량으로 인한 결과로 생각된다. A-1, A-2, A-3 아이 스크림은 유지방만을 원료로 사용한 carton 형태의 제품이지 만, A-4는 원뿔 형태의 과자가 아이스크림을 담고 있는 제품 으로 유지방 이외에 가공버터, 과자와 chocolate에 식물성유 지가 함유되어 있다(Table 1). 본 연구에서는 시료 전체를 녹 이고 균질화한 후 조지방을 추출하였는데, A-4는 원뿔형 과 자와 chocolate의 지방도 같이 추출되어 제조사에서 제공한 유지방 함량 $(7 \%)$ 보다 조지방 함량 $(11.35 \pm 0.65 \%)$ 이 높았다. 프랜차이즈 '아이스크림'은 모두 carton형태의 제품으로, 조 지방 함량은 B-2와 B-4가 B-1와 B-3보다 유의적으로 높았다 $(\mathrm{p}<0.05) . \mathrm{B}-2$ 와 B-4는 초콜릿 아이스크림으로 함유된 초콜 릿의 지방으로 인해 조지방 함량이 높은 것으로 보이며, 국가 표준식품성분표에서 ‘아이스크림(초콜릿맛)'의 지방함량( 11.0 $\mathrm{g} / 100 \mathrm{~g}$ )과 유사하였다(NAS, 2016).

'아이스밀크'인 C-1은 물고기 모양의 과자가 아이스크림 을 덮은 형태이고, C-6은 분쇄쿠키가 혼합된 아이스크림을 카스텔라가 샌드위치처럼 양쪽으로 덮은 형태이며, 다른 제 품들은 bar 형태이었다. C-1, C-3, C-4, C-6의 조지방 함량은 다른 5 개 제품보다 유의적으로 높고 $(\mathrm{p}<0.05)$, 가장 낮은 $\mathrm{C}-2$ 보 다 2 배 이상 높았다 $(\mathrm{p}<0.05)$. 아이스밀크는 유지방 $(2-6 \mathrm{w} / \mathrm{v} \%)$ 이외 야자유와 팜유 및 식물성유지 $(\mathrm{C}-1, \mathrm{C}-3, \mathrm{C}-4, \mathrm{C}-6)$ 를 함 유하고 있어, 아이스밀크의 종류에 따라 라벨에 제시된 유지 방 함량보다 조지방 함량이 높았다. '샤베트'는 모두 bar 형 태로서 조지방 함량은 D-4가 가장 높고, D-1, D-3, D-2 순으 로 유의적으로 높았다 $(\mathrm{p}<0.05)$. 샤베트는 일반적으로 $1-4 \%$
의 유지방과(Goff, 2016), 그 외 식물성유지가 제조 시 첨가 되는데(Smith, 2015), D-1과 D-4에는 야자유가 함유되어 있 었다. '비유지방 아이스크림'에는 탈지분유, 팜유와 야자유, ‘빙과'에는 야자유와 야자경화유가 미량 함유되어 있다.

식품공전에 명시된 아이스크림과 아이스밀크의 유지방 함 량의 기준 규격은 각각 $6 \%$ 와 $2 \%$ 이상이고, 분석된 조지방 함량은 그 이상으로, 유지방이 기준 이상으로 더 함유되거나 (A-2, A-3 제외), 이외의 지방이 첨가되어 제조된 것으로 보 인다. 또한, 아이스크림류는 종류에 따라 기본적인 카툰 형태 외에 부재료(초콜릿, 과자, 카스텔라, 쿠키)가 첨가됨에 따라 유지방 이외에 야자유, 팜유 등의 식물성유지가 동시에 함유 되어 아이스크림의 조지방을 이루고 있으며, 이 부재료들에 의해 조지방이 함량이 높은 것으로 확인되었다.

\section{아이스크림 유형별 콜레스테롤 함량}

시중 유통되는 아이스크림의 콜레스테롤 함량은 일반‘아 이스크림' $22.80-27.34 \mathrm{mg} / 100 \mathrm{~g}$, 프랜차이즈 '아이스크림' $25.26-29.65 \mathrm{mg} / 100 \mathrm{~g}$, '아이스밀크' $8.96-20.72 \mathrm{mg} / 100 \mathrm{~g}$, ‘샤베트' $3.70-5.76 \mathrm{mg} / 100 \mathrm{~g}$, '비유지방 아이스크림' 0-4.29 $\mathrm{mg} / 100 \mathrm{~g}$ 으로 분석되어, 콜레스테롤 함량은 프랜차이즈 '아 이스크림' 제품이 가장 높고, 다음으로 일반 '아이스크림', '아이스밀크', '샤베트', '비유지방 아이스크림' 제품 순으로 높은 경향을 보였으며, 빙과 제품에서는 검출되지 않았다 (Table 2). 포장 라벨에 제공된 영양성분표의 콜레스테롤 함 량은 일반‘아이스크림' 9-25 mg/100 mL, ‘아이스밀크' 2-21 $\mathrm{mg} / 100 \mathrm{~mL}$, ‘샤베트' $6-7 \mathrm{mg} / 100 \mathrm{~mL}$, '비유지방 아이스크 림' 0-4 mg/100 mL이며, '빙과'의 경우 모두 $0 \mathrm{mg} / 100 \mathrm{~mL}$ 로 표기되어 있어(Table 2), 본 연구에서 분석된 콜레스테롤 함량 $(\mathrm{mg} / 100 \mathrm{~g})$ 을 포장 라벨에 표기된 함량 $(\mathrm{mg} / 100 \mathrm{~mL})$ 과 비교하면 일반 '아이스크림'과 '아이스밀크' 제품에서는 높 고, ‘샤베트' 제품에서는 낮은 경향을 보였다.

일반 ‘아이스크림'의 콜레스테롤 함량은 A-2, A-1, A-3, $\mathrm{A}-4$ 의 순으로 높았다 $(\mathrm{p}<0.05)$. 유지방 함량이 가장 낮게 표 기된 A-4의 콜레스테롤 함량이 가장 낮고, 유지방 함량이 많 은 A-1와 A-2의 콜레스테롤 함량이 높게 분석되어(Table 1), 아이스크림의 콜레스테롤 함량은 함유된 유지방 함량이 높을 수록 증가하였다(Kilara와 Chandan, 2007; Oh 등, 2001). 프 랜차이즈 ‘아이스크림’의 콜레스테롤 함량은 B-3이 가장 높 고, $\mathrm{B}-2$ 가 가장 낮았다 $(\mathrm{p}<0.05)$. 조지방 함량은 프랜차이즈 ‘아이스크림’이 일반 ‘아이스크림’보다 낮지만, 콜레스테롤 함량은 프랜차이즈 '아이스크림'에서 높았다. 이는 프랜차이 즈 ‘아이스크림'이 프리미엄 아이스크림으로 분류되는바, 지 방의 주원료로 유지방을 많이 함유하고 있어 콜레스테롤 함 량이 높다고 생각된다. '아이스밀크'의 콜레스테롤은 C-4가 
Table 2. Cholesterol content analyzed and provided in packaging label of the commercial ice cream products

\begin{tabular}{|c|c|c|c|}
\hline \multirow[b]{2}{*}{$\begin{array}{l}\text { Type of } \\
\text { products }\end{array}$} & \multirow[b]{2}{*}{ No. } & Analyzed & Packaging label \\
\hline & & $\begin{array}{l}\text { Content of } \\
\text { cholesterol } \\
(\mathrm{mg} / 100 \mathrm{~g})\end{array}$ & $\begin{array}{c}\text { Content of } \\
\text { cholesterol } \\
(\mathrm{mg} / 100 \mathrm{~mL})\end{array}$ \\
\hline \multirow{4}{*}{$\begin{array}{l}\text { Regular } \\
\text { 'ice } \\
\text { creams' }\end{array}$} & A1 & $26.43 \pm 0.55^{1 \mathrm{ab} 2)}$ & 25.00 \\
\hline & $\mathrm{A} 2$ & $27.34 \pm 0.92^{\mathrm{a}}$ & 15.00 \\
\hline & $\mathrm{A} 3$ & $25.34 \pm 0.54^{\mathrm{b}}$ & 10.53 \\
\hline & A4 & $22.80 \pm 0.24^{\mathrm{c}}$ & 8.82 \\
\hline \multirow{4}{*}{$\begin{array}{c}\text { Franchised } \\
\text { 'ice } \\
\text { creams' }\end{array}$} & B1 & $28.32 \pm 0.12^{\mathrm{ab}}$ & $-3)$ \\
\hline & B2 & $25.26 \pm 1.61^{\mathrm{c}}$ & - \\
\hline & B3 & $29.65 \pm 0.54^{\mathrm{a}}$ & - \\
\hline & B4 & $26.75 \pm 0.26^{\mathrm{bc}}$ & - \\
\hline \multirow{9}{*}{$\begin{array}{l}\text { 'Ice } \\
\text { milks' }\end{array}$} & $\mathrm{Cl}$ & $8.96 \pm 1.15^{\mathrm{f}}$ & 2.00 \\
\hline & $\mathrm{C} 2$ & $14.31 \pm 0.07^{\mathrm{d}}$ & 14.29 \\
\hline & C3 & $17.41 \pm 0.59^{c}$ & 14.29 \\
\hline & $\mathrm{C} 4$ & $20.72 \pm 1.38^{\mathrm{a}}$ & 21.43 \\
\hline & $\mathrm{C} 5$ & $17.89 \pm 1.31^{\mathrm{bc}}$ & 18.75 \\
\hline & C6 & $11.49 \pm 0.04^{\mathrm{e}}$ & 16.67 \\
\hline & $\mathrm{C} 7$ & $17.91 \pm 0.47^{\mathrm{bc}}$ & 7.69 \\
\hline & $\mathrm{C} 8$ & $19.70 \pm 1.20^{\mathrm{ab}}$ & 15.38 \\
\hline & C9 & $19.26 \pm 0.10^{\mathrm{abc}}$ & 7.69 \\
\hline \multirow{4}{*}{ 'Sherbets' } & D1 & $4.09 \pm 0.06^{\mathrm{b}}$ & $<7.14$ \\
\hline & D2 & $3.70 \pm 0.32^{\mathrm{b}}$ & 7.14 \\
\hline & D3 & $5.33 \pm 0.00^{\mathrm{a}}$ & 5.95 \\
\hline & D4 & $5.76 \pm 0.51^{\mathrm{a}}$ & 5.95 \\
\hline \multirow{2}{*}{$\begin{array}{l}\text { 'Nonfat ice } \\
\text { creams' }\end{array}$} & E1 & $\mathrm{ND}^{4)}$ & 0.00 \\
\hline & E2 & $2.41 \pm 0.33$ & 4.29 \\
\hline \multirow{2}{*}{$\begin{array}{l}\text { 'Water } \\
\text { ices' }\end{array}$} & $\mathrm{F} 1$ & ND & - \\
\hline & $\mathrm{F} 2$ & ND & - \\
\hline
\end{tabular}

가장 높고, $\mathrm{C}-1$ 가 가장 낮았다. 제품의 영양성분표에 제공된 콜레스테롤 함량과 비교하면, 3개 제품(C-4, 5, 6)을 제외한 제품들에서 높게 분석되었다. 아이스밀크의 조지방 함량과 콜레스테롤 함량은 양의 비례관계에 있지 않았으며, 이는 아
이스밀크의 조지방은 함유된 유지방과 그 외 지방에 의해 함 량이 결정되지만, 콜레스테롤은 함유된 유지방함량에 의해 영향을 받기 때문으로 생각된다. '샤베트'에서는 D-3와 D-4 가 D-1과 D-2보다 유의적으로 높았으며 $(\mathrm{p}<0.05)$, 분석된 D-1과 D-2의 콜레스테롤 함량은 영양분석표에 표기된 함량 보다 낮았다. D-3과 D-4는 지방원료로 원유와 dairy spread 가 함께 사용되었고, D-1, D-2에는 dairy spread만 첨가되어 콜레스테롤 함량에 차이가 있는 것으로 보인다. '비유지방 아 이스크림' 제품에서는 E-2 제품에서만 $2.23 \mathrm{mg} / 100 \mathrm{~g}$ 으로 소량 분석되었고, 제공된 영양성분표에는 $4 \mathrm{mg} / 100 \mathrm{~mL}$ 로 표 기되어 있었다(Table 2).

시중 유통되는 아이스크림 중 프랜차이즈 ‘아이스크림' 제 품에서 콜레스테롤이 가장 높고, 다음으로 유지방 함량이 높 은 일반 아이스크림과 아이스밀크 순으로 높게 분석되었다. 아이스크림의 품질은 유지방 함량이 높을수록 프리미엄 아이 스크림으로 분류되어 인식되므로, 구입하는 소비자에게 제품 에 함유된 콜레스테롤 함량을 정확히 제공하여야 하지만, 본 연구에서 분석한 함량과 영양분석표에 제공된 함량과는 유사 하거나 함량의 차이가 있음을 확인하였다. 또한, 아이스크림 제조에 이용된 야자유 등의 식물성유지는 다량의 포화지방산 을 함유하여 섭취 시 혈중 콜레스테롤 농도에 영향을 줄 수 있으므로(Keszycka 등, 2013; Ohlsson, 2010), 제조사는 유 지방 이외의 식물성유지(야자유, 팜유 등)의 첨가 재료들 과 함량을 소비자들에게 정확히 제공하는 것이 바람직하 다고 생각한다.

\section{아이스크림 유형별 지방산 조성}

일반 '아이스크림'의 총포화지방산과 총불포화지방산 함 량은 64.4-70.8\%와 29.2-35.6\%으로 포화지방산이 불포화지 방산보다 약 3 배 높았다. 주요지방산으로 palmitic acid(C16:0, $30.0-35.4 \%)$ 가 가장 많고, oleic(C18:1, 18.6-25.1\%), stearic (C18:0, 11.4-16.4\%), myristic(C14:0, 9.1-12.7\%), lauric (C12:0, 3.1-9.1\%), capric $\operatorname{acid}(\mathrm{C} 10: 0,1.7-2.0 \%)$ 의 순으로 높았다(Table 3). 트랜스지방산은 소량(C18:1t, 1.8-3.8\%) 또 는 미량(C18:2t, 0.3-1.1\%; C18:3t, 0.0-0.1\%) 함유되었고, 대 조군으로 분석한 버터의 지방산조성과 유사하였다(Table 3). A-4는 다른 제품들과 비교하여 palmitic과 stearic acid의 함 량은 낮고, lauric와 linoleic $\operatorname{acid}(\mathrm{C} 18: 2)$ 의 함량은 높았는데, 특히 lauric acid는 약 3 배 정도 높았다. 따라서, A-4는 유지 방 외에 lauric acid 함량이 높은 유지가 함유되어 지방산 조 성이 다른 일반 아이스크림과 상이한 것으로 보인다. A-4의 포장 라벨에는 유지방 외에 가공버터, 쇼트닝(부분경화유, 과 자), 식물성유지(초콜릿)가 함유되어 있음을 표기하고 있지 만, 유지의 종류는 제공하지 않았다(Table 1). 본 연구결과와 
Table 3. Fatty acid composition of crude fat in regular 'ice cream' and franchised 'ice cream'

(unit: Area\%)

\begin{tabular}{|c|c|c|c|c|c|c|c|c|c|}
\hline \multirow{2}{*}{ Fatty acid } & \multicolumn{4}{|c|}{ Regular ice creams } & \multirow{2}{*}{$\begin{array}{c}\text { Butter } \\
\mathrm{T}-1\end{array}$} & \multicolumn{4}{|c|}{ Franchised ice creams } \\
\hline & A-1 & A-2 & A-3 & A-4 & & B-1 & B-2 & B-3 & B-4 \\
\hline $\mathrm{C} 4: 0$ & $0.3 \pm 0.1^{1)}$ & $0.6 \pm 0.1$ & -2) & $0.8 \pm 0.1$ & $0.6 \pm 0.0$ & $1.2 \pm 0.2^{\mathrm{a} 3)}$ & $0.9 \pm 0.2^{\mathrm{a}}$ & $1.4 \pm 0.1^{\mathrm{a}}$ & $1.1 \pm 0.2^{\mathrm{a}}$ \\
\hline C6:0 & $0.4 \pm 0.2$ & $0.7 \pm 0.1$ & $0.5 \pm 0.1$ & $0.6 \pm 0.0$ & $3.8 \pm 1.7$ & $1.1 \pm 0.2$ & $0.8 \pm 0.0$ & $1.0 \pm 0.0$ & $0.9 \pm 0.0$ \\
\hline $\mathrm{C} 8: 0$ & $0.6 \pm 0.1$ & $0.6 \pm 0.1$ & $0.6 \pm 0.0$ & $1.2 \pm 0.1$ & $0.7 \pm 0.0$ & $0.6 \pm 0.0$ & $0.5 \pm 0.0$ & $0.6 \pm 0.0$ & $0.9 \pm 0.1$ \\
\hline $\mathrm{C} 10: 0$ & $2.0 \pm 0.2^{\mathrm{a}}$ & $1.7 \pm 0.1^{\mathrm{b}}$ & $2.0 \pm 0.1^{\mathrm{a}}$ & $2.0 \pm 0.0^{\mathrm{ab}}$ & $2.1 \pm 0.1^{\mathrm{a}}$ & $1.9 \pm 0.2^{\mathrm{a}}$ & $1.5 \pm 0.0^{\mathrm{b}}$ & $2.0 \pm 0.0^{\mathrm{ab}}$ & $1.8 \pm 0.1^{\mathrm{a}}$ \\
\hline $\mathrm{C} 12: 0$ & $3.8 \pm 0.2^{\mathrm{b}}$ & $3.3 \pm 0.1^{\mathrm{b}}$ & $3.1 \pm 0.0^{\mathrm{b}}$ & $9.1 \pm 0.5^{\mathrm{a}}$ & $3.5 \pm 0.0^{\mathrm{b}}$ & $3.5 \pm 0.2^{\mathrm{a}}$ & $2.8 \pm 0.0^{\mathrm{b}}$ & $3.1 \pm 0.0^{\mathrm{b}}$ & $2.3 \pm 0.1^{\mathrm{c}}$ \\
\hline $\mathrm{C} 14: 0$ & $12.7 \pm 0.4^{\mathrm{a}}$ & $11.1 \pm 0.2^{\mathrm{c}}$ & $11.7 \pm 0.1^{\mathrm{b}}$ & $9.1 \pm 0.1^{\mathrm{d}}$ & $11.0 \pm 0.1^{\mathrm{c}}$ & $10.4 \pm 0.5^{\mathrm{a}}$ & $9.1 \pm 0.1^{\mathrm{b}}$ & $10.4 \pm 0.0^{\mathrm{a}}$ & $9.3 \pm 0.1^{\mathrm{b}}$ \\
\hline $\mathrm{C} 14: 1$ & $1.0 \pm 0.2$ & $0.9 \pm 0.0$ & $1.0 \pm 0.0$ & $0.4 \pm 0.0$ & $0.8 \pm 0.0$ & $0.6 \pm 0.3$ & $0.5 \pm 0.0$ & $0.6 \pm 0.0$ & $0.7 \pm 0.0$ \\
\hline C16:0 & $34.6 \pm 0.9^{\mathrm{ab}}$ & $35.4 \pm 0.2^{\mathrm{a}}$ & $33.3 \pm 0.3^{\mathrm{b}}$ & $30.0 \pm 0.0^{\mathrm{c}}$ & $33.3 \pm 0.4^{\mathrm{b}}$ & $33.0 \pm 0.6^{\mathrm{ab}}$ & $32.4 \pm 0.1^{\mathrm{b}}$ & $33.5 \pm 0.0^{\mathrm{a}}$ & $30.9 \pm 0.1^{\mathrm{c}}$ \\
\hline $\mathrm{C} 16: 1$ & $1.7 \pm 0.1$ & $1.7 \pm 0.0$ & $1.8 \pm 0.0$ & $0.9 \pm 0.0$ & $1.0 \pm 1.1$ & $1.6 \pm 0.1$ & $1.5 \pm 0.0$ & $1.6 \pm 0.0$ & $1.6 \pm 0.0$ \\
\hline $\mathrm{C} 18: 0$ & $16.4 \pm 3.5^{\mathrm{a}}$ & $14.4 \pm 0.4^{\mathrm{ab}}$ & $15.5 \pm 0.1^{\mathrm{ab}}$ & $11.4 \pm 0.5^{\mathrm{b}}$ & $13.1 \pm 0.2^{\mathrm{ab}}$ & $16.3 \pm 0.2^{\mathrm{c}}$ & $19.5 \pm 0.3^{\mathrm{a}}$ & $16.3 \pm 0.0^{\mathrm{c}}$ & $17.7 \pm 0.4^{\mathrm{b}}$ \\
\hline C18:1t & $3.8 \pm 0.1^{\mathrm{a}}$ & $3.2 \pm 0.0^{\mathrm{b}}$ & $3.8 \pm 0.1^{\mathrm{a}}$ & $1.8 \pm 0.1^{\mathrm{d}}$ & $2.1 \pm 0.0^{\mathrm{c}}$ & $2.5 \pm 0.1^{\mathrm{b}}$ & $1.8 \pm 0.0^{\mathrm{c}}$ & $2.6 \pm 0.0^{\mathrm{b}}$ & $3.7 \pm 0.0^{\mathrm{a}}$ \\
\hline C18:1(n-9)c & $18.6 \pm 1.4^{\mathrm{c}}$ & $22.2 \pm 0.0^{\mathrm{b}}$ & $22.9 \pm 0.5^{\mathrm{ab}}$ & $25.1 \pm 0.4^{\mathrm{a}}$ & $24.3 \pm 1.1^{\mathrm{ab}}$ & $22.6 \pm 0.4^{\mathrm{b}}$ & $24.5 \pm 0.1^{\mathrm{a}}$ & $22.8 \pm 0.1^{\mathrm{b}}$ & $24.2 \pm 0.4^{\mathrm{a}}$ \\
\hline $\mathrm{C} 18: 1(\mathrm{n}-7) c$ & $0.4 \pm 0.0$ & $0.6 \pm 0.0$ & $0.6 \pm 0.0$ & $0.7 \pm 0.0$ & $0.4 \pm 0.0$ & $0.5 \pm 0.0$ & $0.5 \pm 0.0$ & $0.5 \pm 0.0$ & $0.6 \pm 0.0$ \\
\hline $\mathrm{C} 18: 2 t$ & $1.1 \pm 0.0$ & $1.0 \pm 0.1$ & $0.3 \pm 0.0$ & $0.4 \pm 0.0$ & - & $0.9 \pm 0.3^{\mathrm{a}}$ & $0.4 \pm 0.1^{\mathrm{a}}$ & $0.9 \pm 0.3^{\mathrm{a}}$ & $0.9 \pm 0.0^{\mathrm{a}}$ \\
\hline $\mathrm{C} 18: 2(\mathrm{n}-6) c$ & $1.4 \pm 0.1^{\mathrm{d}}$ & $1.7 \pm 0.0^{\mathrm{c}}$ & $1.8 \pm 0.0^{\mathrm{c}}$ & $5.1 \pm 0.0^{\mathrm{a}}$ & $2.4 \pm 0.0^{\mathrm{b}}$ & $2.1 \pm 0.1^{\mathrm{bc}}$ & $2.2 \pm 0.0^{\mathrm{ab}}$ & $2.1 \pm 0.0^{\mathrm{c}}$ & $2.3 \pm 0.0^{\mathrm{a}}$ \\
\hline C20:0 & $0.2 \pm 0.1$ & $0.2 \pm 0.0$ & $0.2 \pm 0.0$ & $0.3 \pm 0.0$ & $0.2 \pm 0.0$ & $0.2 \pm 0.0$ & $0.4 \pm 0.0$ & $0.2 \pm 0.0$ & $0.4 \pm 0.0$ \\
\hline C18:3(n-6) & - & - & $0.1 \pm 0.0$ & - & $0.1 \pm 0.0$ & - & - & - & - \\
\hline $\mathrm{C} 18: 3 t$ & $0.1 \pm 0.0$ & $0.1 \pm 0.0$ & $0.0 \pm 0.0$ & $0.1 \pm 0.0$ & - & $0.2 \pm 0.0$ & $0.2 \pm 0.0$ & $0.2 \pm 0.0$ & $0.2 \pm 0.0$ \\
\hline C20:1 & $0.5 \pm 0.7$ & - & $0.0 \pm 0.0$ & $0.2 \pm 0.0$ & $0.1 \pm 0.0$ & $0.1 \pm 0.0$ & $0.1 \pm 0.0$ & $0.1 \pm 0.0$ & $0.0 \pm 0.1$ \\
\hline C18:3(n-3) & $0.3 \pm 0.4$ & $0.4 \pm 0.0$ & $0.7 \pm 0.0$ & $0.4 \pm 0.0$ & $0.2 \pm 0.0$ & $0.3 \pm 0.0$ & $0.2 \pm 0.0$ & $0.2 \pm 0.0$ & $0.5 \pm 0.0$ \\
\hline C20:3n6 & $0.1 \pm 0.0$ & $0.1 \pm 0.0$ & - & $0.4 \pm 0.1$ & $0.1 \pm 0.0$ & $0.2 \pm 0.0$ & $0.1 \pm 0.0$ & $0.2 \pm 0.0$ & $0.1 \pm 0.0$ \\
\hline C20:4(n-6) & $0.1 \pm 0.0$ & $0.1 \pm 0.0$ & - & $0.1 \pm 0.0$ & $0.2 \pm 0.0$ & $0.2 \pm 0.0$ & $0.2 \pm 0.0$ & $0.2 \pm 0.0$ & $0.2 \pm 0.0$ \\
\hline Total $\mathrm{SFA}^{4)}$ & $70.8 \pm 2.3$ & $68.1 \pm 1.2$ & $66.9 \pm 0.7$ & $64.4 \pm 0.2$ & $68.3 \pm 2.4$ & $68.2 \pm 0.5$ & $67.8 \pm 0.1$ & $68.2 \pm 0.2$ & $65.1 \pm 0.4$ \\
\hline Total USFA $^{5)}$ & $29.2 \pm 2.3$ & $31.9 \pm 0.2$ & $33.1 \pm 0.7$ & $35.6 \pm 0.2$ & $31.7 \pm 2.4$ & $31.8 \pm 0.5$ & $32.2 \pm 0.1$ & $31.8 \pm 0.2$ & $34.9 \pm 0.4$ \\
\hline
\end{tabular}

유사하게 Shin 등(2006)은 일반 ‘아이스크림' 제품 중 lauric acid가 28\%까지 함유된 제품을 보고하였고, 유지방 이외의 지방이 첨가됨을 시사하였다.

식품공전에서는 아이스크림의 유지방 함량을 $6 \%$ 이상으 로 규정하고 있으나, 유지방 이외 지방의 사용 규정에 대해서 는 명시되어 있지 않다(MFDS, 2019). 따라서 식물성유지는 아이스크림의 부재료로 사용될 수 있으며, 주로 야자유, 팜 유, 팜핵유 등이 이용된다(Clarke, 2015; Goff, 2016; Smith,
2015; Underdown 등, 2011). 야자유의 주요지방산은 lauric (47.7\%), myristic(19.9\%), oleic(15.1\%), palmitic(7.9\%), stearic acid(2.7\%), 팜핵유는 lauric(48.4\%), myristic(15.6\%), oleic(15.1\%), stearic $\operatorname{acid}(7.9 \%)$, 팜유는 palmitic(43.2\%), oleic(39.1\%), linoleic(10.7\%), stearic $\operatorname{acid}(4.6 \%)$ 이다(Smith, 2015). 특히 야자유와 팜핵유는 lauric acid의 함량이 가장 많 아, 이들 유지를 첨가한 아이스크림 제품에서는 다른 제 품들보다 lauric acid 함량이 높았으며, A-4에 야자유 또는 
팜핵유가 지방재료로 같이 사용되었을 것으로 생각된다.

프랜차이즈 ‘아이스크림’의 총포화지방산과 총불포화지방 산 함량은 $65.1-68.2 \%$ 와 $31.8-34.9 \%$ 이고, 주요지방산은 palmitic(30.9-33.5\%), oleic(22.6-24.5\%), stearic(16.3-19.5\%), myristic acid(9.1-10.4\%)이며, 그 외 lauric, capric, butryric acid와 트랜스지방산(C18:1t, 1.8-3.7\%; C18:2t, 0.4-0.9\%; $\mathrm{C} 18: 3 t, 0.2 \%)$ 을 소량 함유하고 있으며, 버터의 지방산 조성 과 유사하였다(Table 3). Kuhnt 등(2011)은 버터에는 트랜스 지방산이 약 $3.15 \%$ 존재하고, 이중 $\mathrm{C} 18: 1$ 의 트랜스지방산이 대부분이고, 특히 $t 11-\mathrm{C} 18: 1$ 이 많이 분포하고, $t 9 \sim t 16-\mathrm{C} 18: 1$ 의 다양한 트랜스지방산도 존재한다고 보고하였다.

'아이스밀크'의 주요지방산은 palmitic(23.3-39.7\%), oleic (11.3-23.2\%), stearic(9.7-18.5\%), myristic(9.4-15.5\%), lauric $\operatorname{acid}(2.8-24.4 \%)$ 이고, 소량의 트랜스지방산 $(\mathrm{C} 18: 1 t, 1.2-3.3 \%$; $\mathrm{C} 18: 2 t, 0.1-0.5 \%)$ 이 함유되었다(Table 4). 이 중 lauric acid 의 함량 범위는 다양하여, C-1(24.4\%)에 가장 많고, C-6, $\mathrm{C}-3, \mathrm{C}-4$ 에는 각각 $18.7 \%, 12.8 \%, 4.7 \%$ 존재하며. 그 외의 아이스밀크에는 2.8-3.5\% 함유되었고, 특히 C-1, C-3, C-6에 서는 버터보다 약 6-8배 높았다. 또한, lauric acid의 함량이 높은 제품들에서는 버터의 지방산 조성(oleic, $24.3 \%$; myristic acid, $11.0 \%)$ 과 비교하여 상대적으로 oleic acid의 함량(C-1, $13.2 \%$; C-6, 11.4\%)이 낮거나, myristic acid(C-1, 15.5\%)의 함량은 높은 경향을 보였다. C-1, C-3, C-4와 C-6는 포장 라 벨에 식물성유지(야자유), C-2, C-3, C-4는 '가공버터'가 표 기되어 있다. 가공버터는 대부분 버터에 식물성유지를 교반 하여 가공되는데 C-3와 C-4는 가공버터에 제조된 식물성유 지를 야자유로 표기되고 있지만, C-2에서는 제공하지 않았 다. 야자유는 lauric(47.7\%), myristic acid(18.2\%)가 주된 지 방산이므로(Smith, 2015), 야자유가 첨가된 C-1, C-3, C-6에 서 lauric acid가 높게 분석됨을 확인하였다. 국내에서 제조되 는 아이스밀크는 유지방분 $2 \%$ 이상 함유를 기준 규격화하고 있다. 본 연구에서는 아이스밀크 제품들에서 유지방 이외의 식물성유지가 첨가된 제품이 있음을 확인하였고, 지방산 분 석을 통해 제조사의 라벨에 표기된 지방 원재료의 종류와 유 사함을 확인하였다.

'샤베트'에는 포화지방산함량이 불포화지방산함량보다 2.1-5.2배 높고, 주요지방산은 lauric(3.2-33.4\%,) palmitic (17.8-34.5\%), oleic(12.0-22.3\%), stearic(7.2-14.3\%), myristic $\operatorname{acid}(12.5-17.2 \%)$ 이고, 소량의 트랜스지방산(C18:1t, 1.0-3.6\%) 을 함유하였다. D-2의 지방산 조성은 버터와 유사하지만, D-1, D-3, D-4는 lauric acid를 각각 $28.4 \%, 17.1 \%, 33.4 \%$ 으 로 함유하고, 버터의 lauric acid(3.3\%) 함량보다 각각 8.6배, 5.2 배, 10.1배 높았다. D-1과 D-4의 포장 라벨에 lauric acid 함량이 많은 야자유를 표기하여, 지방산 조성 분석결과와 일
치하였지만, D-3는 식물성유지에 관한 정보제공이 없었다.

‘비유지방 아이스크림' E-1은 palmitic(44.3\%)과 oleic $\operatorname{acid}(35.9 \%)$ 가 전체 지방산의 $80.2 \%$ 를, E-2는 lauric( $27.2 \%)$, palmitic(21.6\%), oleic(19.5\%)와 myristic acid(13.2\%)가 전 체의 $81.5 \%$ 를 함유하여 지방산 조성이 현저히 상이하였다 (Table 5). 포장 라벨로부터 E-1의 원재료에 정제 팜유가 함 유됨을 확인하였고, 분석결과 팜유의 지방산 조성과 일치하 였다. E-2는 야자유와 부재료인 분쇄쿠키에 팜유가 표기되어 있고, 지방산 분석 결과 lauric, palmitic, oleic acid의 분포가 높아 이들 식물성유지가 첨가됨을 예측할 수 있었다.

'빙과'에는 지방이 미량(0.17-0.7\%)으로 함유되어 있고, 대부분 포화지방산(80.7-96.47\%)으로 구성되었다(Table 5). F-1은 stearic(38.9\%), palmitic(38.9\%)과 oleic acid(12.3\%) 가 전체 지방산의 $89.7 \%$ 이고, 포장 라벨에는 야자유가 표기 되어 있지만, 분석결과와는 상이하였다. F-2의 주요지방산은 lauric(28.8\%), stearic(26.5\%), palmitic(22.5\%), myristic acid $(13.9 \%)$ 이었는데, 이는 라벨에 표기된 '야자경화유'가 첨가 된 결과로 생각된다. 야자경화유는 야자유를 수소화 반응으 로 경화시킨 것으로 포화지방산을 다량 함유하고 있다(Jeong 등, 2009).

\section{요 약}

국내 유통되는 아이스크림 제품의 유형별 조지방과 콜레 스테롤 함량 및 지방산 조성을 분석하고, 제품 포장 라벨에 표기된 내용과 비교하였다. 제품 유형별 조지방 함량은 일반 ‘아이스크림'(7.00-12.49\%), 프랜차이즈 ‘아이스크림'(6.27$11.02 \%)$, '아이스밀크'(2.99-7.14\%), '비유지방 아이스크림' (5.43-6.03\%), ‘샤베트'(1.48-4.21\%), ‘빙과’(0.17-0.76\%)의 순으로 높았다. 포장 라벨에 제공된 유지방과 조지방 함량은 식품공전의 기준 규격인 아이스크림과 아이스밀크(유지방 $6 \%$ 와 $2 \%$ 이상), 비유지방 아이스크림(조지방 $5 \%$ 이상)에 부합되지만, 분석결과 일반 아이스크림 2 개 제품의 조지방 함량은 표기된 유지방 함량보다 낮았으며, 조지방 함량이 유 지방 함량보다 높은 아이스크림은 식물성유지를 첨가한 것으 로 확인되었다. 콜레스테롤 함량은 프랜차이즈 '아이스크 림'(25.26-29.65 mg/100 g), 일반 '아이스크림'(22.80-27.34 $\mathrm{mg} / 100 \mathrm{~g})$, ‘아이스밀크'(8.96-20.72 mg/100 g), ‘샤베트'(3.70$5.76 \mathrm{mg} / 100 \mathrm{~g})$, ‘비유지방 아이스크림' $(0-2.41 \mathrm{mg} / 100 \mathrm{~g})$ 순 으로 높고, 빙과 제품에서는 콜레스테롤이 검출되지 않았다. 콜레스테롤 함량은 영양성분표와 비교하여 일반아이스크림 4 개 제품과, 아이스밀크 5 개 제품에서는 높게 분석되었다. 아 이스크림의 포화지방산은 불포화지방산보다 약 2-4배 정도 높고, 일반 아이스크림과 프랜차이즈 아이스크림의 주요지방 
Table 4. Fatty acid composition of crude fat in 'ice milk'

(unit: Area\%)

\begin{tabular}{|c|c|c|c|c|c|c|c|c|c|}
\hline \multirow{2}{*}{ Fatty acid } & \multicolumn{9}{|c|}{ Ice milk } \\
\hline & $\mathrm{C}-1$ & $\mathrm{C}-2$ & $\mathrm{C}-3$ & $\mathrm{C}-4$ & $\mathrm{C}-5$ & C-6 & $\mathrm{C}-7$ & $\mathrm{C}-8$ & C-9 \\
\hline $\mathrm{C} 4: 0$ & -1) & - & - & - & - & - & - & - & - \\
\hline C6:0 & $0.6 \pm 0.0^{2)}$ & $1.0 \pm 0.0$ & - & $1.2 \pm 0.3$ & $1.1 \pm 0.0$ & $0.6 \pm 0.1$ & $1.1 \pm 0.1$ & $1.1 \pm 0.1$ & $1.1 \pm 0.0$ \\
\hline $\mathrm{C} 8: 0$ & $2.9 \pm 0.1$ & $0.7 \pm 0.0$ & $1.2 \pm 0.1$ & $0.9 \pm 0.2$ & $0.8 \pm 0.0$ & $2.3 \pm 0.4$ & $0.9 \pm 0.2$ & $0.7 \pm 0.0$ & $0.8 \pm 0.0$ \\
\hline $\mathrm{C} 10: 0$ & $3.4 \pm 0.0^{\mathrm{a} 3)}$ & $2.0 \pm 0.1^{\mathrm{b}}$ & $1.9 \pm 0.3^{\mathrm{c}}$ & $2.5 \pm 0.5^{\mathrm{abc}}$ & $2.3 \pm 0.0^{\mathrm{abc}}$ & $2.7 \pm 0.5^{\mathrm{abc}}$ & $3.1 \pm 1.1^{\mathrm{ab}}$ & $2.3 \pm 0.1^{\mathrm{bc}}$ & $2.4 \pm 0.0^{\mathrm{abc}}$ \\
\hline $\mathrm{C} 12: 0$ & $24.4 \pm 0.1^{\mathrm{a}}$ & $2.8 \pm 0.0^{\mathrm{d}}$ & $12.8 \pm 0.6^{\mathrm{c}}$ & $4.7 \pm 0.9^{d}$ & $3.5 \pm 0.0^{\mathrm{d}}$ & $18.7 \pm 3.6^{\mathrm{b}}$ & $3.5 \pm 0.2^{\mathrm{d}}$ & $3.3 \pm 0.1^{\mathrm{d}}$ & $3.5 \pm 0.0^{\mathrm{d}}$ \\
\hline $\mathrm{C} 14: 0$ & $15.5 \pm 0.0^{\mathrm{a}}$ & $10.4 \pm 0.1^{\mathrm{bc}}$ & $9.4 \pm 0.3^{\mathrm{c}}$ & $12.8 \pm 2.2^{\mathrm{b}}$ & $12.6 \pm 0.0^{\mathrm{b}}$ & $12.7 \pm 2.4^{\mathrm{b}}$ & $12.7 \pm 0.1^{\mathrm{b}}$ & $12.3 \pm 0.1^{\mathrm{b}}$ & $12.7 \pm 0.0^{\mathrm{b}}$ \\
\hline C14:1 & $0.4 \pm 0.0$ & $0.6 \pm 0.0$ & $0.3 \pm 0.1$ & $0.8 \pm 0.1$ & $1.0 \pm 0.0$ & $0.4 \pm 0.1$ & $1.0 \pm 0.0$ & $0.9 \pm 0.0$ & $1.0 \pm 0.0$ \\
\hline $\mathrm{C} 16: 0$ & $23.3 \pm 0.0^{\mathrm{d}}$ & $32.4 \pm 0.1^{\mathrm{bc}}$ & $26.9 \pm 0.2^{\mathrm{cd}}$ & $37.2 \pm 6.3^{\mathrm{ab}}$ & $37.5 \pm 0.1^{\mathrm{ab}}$ & $32.5 \pm 5.4^{\mathrm{bc}}$ & $39.7 \pm 0.8^{\mathrm{a}}$ & $37.5 \pm 0.1^{\mathrm{ab}}$ & $38.9 \pm 0.0^{\mathrm{ab}}$ \\
\hline C16:1 & $0.9 \pm 0.0$ & $1.6 \pm 0.05$ & $0.7 \pm 0.1$ & $1.9 \pm 0.3$ & $2.2 \pm 0.0$ & $1.1 \pm 0.2$ & $2.1 \pm 0.3$ & $2.3 \pm 0.0$ & $2.4 \pm 0.0$ \\
\hline C18:0 & $10.9 \pm 0.2^{\mathrm{bc}}$ & $17.1 \pm 0.0^{\mathrm{a}}$ & $18.5 \pm 0.4^{\mathrm{a}}$ & $17.5 \pm 3.0^{\mathrm{a}}$ & $13.2 \pm 0.1^{\mathrm{b}}$ & $9.8 \pm 1.6^{\mathrm{c}}$ & $11.1 \pm 0.4^{\mathrm{bc}}$ & $12.0 \pm 0.2^{\mathrm{bc}}$ & $10.8 \pm 0.0^{\mathrm{bc}}$ \\
\hline $\mathrm{C} 18: 1 t$ & $1.8 \pm 0.0$ & $3.0 \pm 0.0$ & $1.2 \pm 0.0$ & $3.3 \pm 0.6$ & $3.1 \pm 0.0$ & $1.3 \pm 0.2$ & $2.0 \pm 0.1$ & $2.2 \pm 0.1$ & $2.1 \pm 0.0$ \\
\hline C18:1(n-9)c & $13.2 \pm 0.1^{\mathrm{a}}$ & $23.2 \pm 0.3^{\mathrm{a}}$ & $22.7 \pm 0.5^{\mathrm{a}}$ & $11.9 \pm 15.4^{\mathrm{a}}$ & $19.6 \pm 0.0^{\mathrm{a}}$ & $11.4 \pm 15.8^{\mathrm{a}}$ & $19.3 \pm 0.5^{\mathrm{a}}$ & $21.6 \pm 0.3^{\mathrm{a}}$ & $20.8 \pm 0.1^{\mathrm{a}}$ \\
\hline $\mathrm{C} 18: 1(\mathrm{n}-7) c$ & $0.3 \pm 0.0$ & $0.8 \pm 0.0$ & $0.5 \pm 0.0$ & $0.9 \pm 0.2$ & $0.5 \pm 0.0$ & $0.6 \pm 0.1$ & $0.7 \pm 0.0$ & $0.7 \pm 0.0$ & $0.7 \pm 0.0$ \\
\hline $\mathrm{C} 18: 2 t$ & $0.1 \pm 0.0$ & $0.3 \pm 0.0$ & $0.4 \pm 0.2$ & $0.3 \pm 0.1$ & $0.2 \pm 0.0$ & $0.1 \pm 0.0$ & $0.5 \pm 0.4$ & $0.2 \pm 0.0$ & $0.2 \pm 0.0$ \\
\hline C18:2(n-6)c & $1.5 \pm 0.0^{\mathrm{c}}$ & $3.1 \pm 0.0^{\mathrm{b}}$ & $2.9 \pm 0.0^{\mathrm{b}}$ & $3.5 \pm 0.6^{\mathrm{b}}$ & $1.3 \pm 0.0^{\mathrm{c}}$ & $5.0 \pm 0.8^{\mathrm{a}}$ & $1.5 \pm 0.1^{\mathrm{c}}$ & $2.0 \pm 0.1^{\mathrm{c}}$ & $1.8 \pm 0.0^{\mathrm{c}}$ \\
\hline C20:0 & $0.2 \pm 0.0$ & $0.2 \pm 0.0$ & - & $0.2 \pm 0.0$ & $0.2 \pm 0.0$ & $0.3 \pm 0.0$ & $0.2 \pm 0.0$ & $0.2 \pm 0.0$ & $0.2 \pm 0.0$ \\
\hline C18:3(n-6) & $0.0 \pm 0.1$ & $0.1 \pm 0.1$ & - & - & - & - & - & - & - \\
\hline $\mathrm{C} 18: 3 t$ & - & - & - & - & - & - & $0.1 \pm 0.1$ & - & - \\
\hline C20:1 & $0.1 \pm 0.0$ & $0.1 \pm 0.0$ & $0.2 \pm 0.1$ & - & $0.3 \pm 0.4$ & $0.2 \pm 0.2$ & - & $0.1 \pm 0.0$ & $-1)$ \\
\hline C18:3(n-3) & $0.3 \pm 0.0$ & $0.3 \pm 0.0$ & - & $0.4 \pm 0.1$ & $0.6 \pm 0.0$ & $0.3 \pm 0.1$ & $0.3 \pm 0.0$ & $0.3 \pm 0.0$ & $0.3 \pm 0.0$ \\
\hline C20:3n6 & - & $0.2 \pm 0.0$ & - & - & $0.1 \pm 0.0$ & - & $0.1 \pm 0.0$ & $0.1 \pm 0.0$ & $0.1 \pm 0.0$ \\
\hline$C 20: 4(n-6)$ & - & $0.2 \pm 0.0$ & - & $0.2 \pm 0.1$ & $0.1 \pm 0.0$ & $0.1 \pm 0.0$ & $0.1 \pm 0.0$ & $0.2 \pm 0.0$ & $0.2 \pm 0.0$ \\
\hline Total SFA ${ }^{4)}$ & $81.3 \pm 0.1$ & $66.6 \pm 0.4$ & $71.2 \pm 0.7$ & $76.9 \pm 13.4$ & $71.2 \pm 0.3$ & $79.5 \pm 14.1$ & $72.3 \pm 0.4$ & $69.5 \pm 0.3$ & $70.4 \pm 0.1$ \\
\hline Total USFA ${ }^{5)}$ & $18.7 \pm 0.1$ & $33.4 \pm 0.4$ & $28.8 \pm 0.7$ & $23.1 \pm 13.4$ & $28.8 \pm 0.3$ & $20.5 \pm 14.1$ & $27.7 \pm 0.4$ & $30.5 \pm 0.3$ & $29.6 \pm 0.1$ \\
\hline
\end{tabular}

${ }^{1)}$ Not detected.

${ }^{2)}$ Mean \pm SD $(\mathrm{n}=2)$

${ }^{3)}$ Means in the same row with different letters are significantly different at $\mathrm{p}<0.05$ level.

${ }^{4)}$ Total saturated fatty acids.

${ }^{5)}$ Total unsaturated fatty acids.

산은 palmitic $>$ oleic $>$ stearic $>$ myristic $>$ lauric acid 순이 었으며, 소량의 트랜스지방산도 함유하여 유지방인(버터)와 지방산 조성이 유사하였다. 일반아이스크림 1 개 제품은 유지 방 외에 식물성유지를 함유하여 lauric acid의 함량이 많았다. '아이스밀크'와 ‘사베트' 제품의 지방산 조성은 유지방과 유 사하거나, lauric acid의 함량이 유지방보다 높았는데, 이 경 우 포장 라벨에 야자유를 표시한 제조사도 있지만, 식물성유
지에 관한 정보제공이 없는 제품도 있었다. '비유지방 아이스 크림'의 지방산 조성은 포장 라벨에 지방원으로 명시된 팜유 또는 야자유의 지방산 조성과 유사하였다. 본 연구에서 분석 한 아이스크림의 조지방과 콜레스테롤 함량은 제조사에서 제 공된 정보와 유사하거나 함량의 차이가 있다. 따라서 주기적 으로 유통 아이스크림의 지방 프로파일을 분석하여 모니터링 할 필요성이 있다고 생각된다. 
Table 5. Fatty acids composition of crude fat in 'sherbets' and 'Nonfat ice creams' and 'Water ices'

(unit: Area\%)

\begin{tabular}{|c|c|c|c|c|c|c|c|c|}
\hline \multirow{2}{*}{ Fatty acid } & \multicolumn{4}{|c|}{ Serbets } & \multicolumn{2}{|c|}{ Nonfat ice creams } & \multicolumn{2}{|c|}{ Water ices } \\
\hline & D-1 & D-2 & D-3 & D-4 & E-1 & E-2 & F-1 & $\mathrm{F}-2$ \\
\hline $\mathrm{C} 4: 0$ & $-1)$ & - & - & - & - & - & $0.3 \pm 0.1$ & - \\
\hline C6:0 & $0.6 \pm 0.0^{2)}$ & $0.8 \pm 0.2$ & $0.4 \pm 0.0$ & $0.5 \pm 0.0$ & - & $0.2 \pm 0.0$ & - & - \\
\hline C8:0 & $3.4 \pm 0.0^{\mathrm{a} 3)}$ & $0.3 \pm 0.5^{\mathrm{c}}$ & $1.9 \pm 0.1^{\mathrm{b}}$ & $3.8 \pm 0.1^{\mathrm{a}}$ & - & $3.0 \pm 0.1$ & - & $1.8 \pm 0.0$ \\
\hline $\mathrm{C} 10: 0$ & $3.7 \pm 0.0^{\mathrm{b}}$ & $2.1 \pm 0.1^{\mathrm{d}}$ & $2.5 \pm 0.1^{\mathrm{c}}$ & $3.9 \pm 0.1^{\mathrm{a}}$ & - & $2.9 \pm 0.2$ & - & $2.6 \pm 0.0$ \\
\hline $\mathrm{C} 12: 0$ & $28.4 \pm 0.2^{\mathrm{b}}$ & $3.2 \pm 0.1^{\mathrm{d}}$ & $17.1 \pm 0.5^{\mathrm{c}}$ & $33.4 \pm 0.9^{\mathrm{a}}$ & $0.3 \pm 0.0^{\mathrm{b}}$ & $27.2 \pm 0.4^{\mathrm{a}}$ & $1.3 \pm 0.4^{\mathrm{b}}$ & $28.8 \pm 0.1^{\mathrm{a}}$ \\
\hline $\mathrm{C} 14: 0$ & $16.5 \pm 0.0^{\mathrm{b}}$ & $12.5 \pm 0.1^{\mathrm{c}}$ & $12.8 \pm 0.2^{\mathrm{c}}$ & $17.2 \pm 0.3^{\mathrm{a}}$ & $1.1 \pm 0.0^{\mathrm{b}}$ & $13.2 \pm 0.2^{\mathrm{a}}$ & $0.9 \pm 0.01^{\mathrm{b}}$ & $13.9 \pm 0.0^{\mathrm{a}}$ \\
\hline C14:1 & $0.3 \pm 0.0$ & $0.4 \pm 0.6$ & $0.4 \pm 0.0$ & $0.3 \pm 0.1$ & - & - & - & - \\
\hline C16:0 & $21.4 \pm 0.1^{\mathrm{c}}$ & $34.5 \pm 0.2^{\mathrm{a}}$ & $26.6 \pm 0.2^{\mathrm{b}}$ & $17.8 \pm 0.1^{\mathrm{d}}$ & $44.3 \pm 0.0^{\mathrm{a}}$ & $21.6 \pm 0.0^{\mathrm{b}}$ & $38.5 \pm 4.0^{\mathrm{a}}$ & $22.5 \pm 0.1^{\mathrm{b}}$ \\
\hline $\mathrm{C} 16: 1$ & $0.8 \pm 0.0$ & $2.1 \pm 0.1$ & $1.0 \pm 0.1$ & $0.5 \pm 0.0$ & $0.2 \pm 0.0$ & $0.2 \pm 0.0$ & - & - \\
\hline C18:0 & $8.4 \pm 0.0^{\mathrm{b}}$ & $14.3 \pm 0.1^{\mathrm{a}}$ & $14.0 \pm 0.4^{\mathrm{a}}$ & $7.2 \pm 0.2^{\mathrm{c}}$ & $8.4 \pm 0.5^{\mathrm{a}}$ & $6.8 \pm 0.1^{\mathrm{a}}$ & $38.9 \pm 2.6^{\mathrm{a}}$ & $26.5 \pm 0.2^{b}$ \\
\hline $\mathrm{C} 18: 1 t$ & $1.2 \pm 0.0$ & $3.6 \pm 0.0$ & $1.9 \pm 0.0$ & $1.0 \pm 0.0$ & - & $0.3 \pm 0.0$ & - & $0.2 \pm 0.0$ \\
\hline $\mathrm{C} 18: 1(\mathrm{n}-9) c$ & $13.0 \pm 0.1^{\mathrm{c}}$ & $22.3 \pm 0.8^{\mathrm{a}}$ & $18.3 \pm 0.1^{\mathrm{b}}$ & $12.0 \pm 0.6^{\mathrm{c}}$ & $35.9 \pm 0.5^{\mathrm{a}}$ & $19.5 \pm 0.3^{\mathrm{b}}$ & $12.3 \pm 4.3^{\mathrm{a}}$ & $2.2 \pm 0.2^{\mathrm{a}}$ \\
\hline $\mathrm{C} 18: 1(\mathrm{n}-7) c$ & $0.3 \pm 0.0$ & $0.6 \pm 0.1$ & $0.4 \pm 0.0$ & $0.4 \pm 0.2$ & $0.8 \pm 0.0$ & $0.5 \pm 0.1$ & - & - \\
\hline $\mathrm{C} 18: 2 t$ & - & - & $0.2 \pm 0.0$ & -1) & $0.3 \pm 0.0$ & - & - & - \\
\hline $\mathrm{C} 18: 2(\mathrm{n}-6) c$ & $1.5 \pm 0.0^{\mathrm{c}}$ & $2.3 \pm 0.1^{\mathrm{a}}$ & $2.0 \pm 0.0^{\mathrm{ab}}$ & $1.9 \pm 0.3^{\mathrm{bc}}$ & $8.3 \pm 0.0^{\mathrm{a}}$ & $4.1 \pm 0.2^{\mathrm{b}}$ & $6.1 \pm 1.1^{\mathrm{a}}$ & $1.0 \pm 0.0^{\mathrm{b}}$ \\
\hline C20:0 & $0.2 \pm 0.0$ & - & $0.3 \pm 0.0$ & $0.2 \pm 0.0$ & $0.4 \pm 0.0$ & $0.2 \pm 0.0$ & $0.8 \pm 0.1$ & $0.4 \pm 0.0$ \\
\hline C18:3(n-6) & - & - & - & - & - & - & - & - \\
\hline $\mathrm{C} 18: 3 t$ & - & - & - & - & - & - & - & - \\
\hline C20:1 & - & - & - & - & $0.1 \pm 0.0$ & $0.1 \pm 0.0$ & - & - \\
\hline C18:3(n-3) & $0.3 \pm 0.1$ & - & $0.3 \pm 0.0$ & $0.1 \pm 0.0$ & $0.1 \pm 0.0$ & $0.1 \pm 0.0$ & $0.9 \pm 0.1$ & $0.1 \pm 0.0$ \\
\hline C20:2 & - & $1.0 \pm 0.0$ & - & - & - & - & - & $0.1 \pm 0.0$ \\
\hline C20:3n6 & - & - & - & - & - & - & $0.3 \pm 0.4$ & - \\
\hline C20:4(n-6) & - & - & - & - & - & - & - & $0.1 \pm 0.0$ \\
\hline Total $\mathrm{SFA}^{4)}$ & $82.6 \pm 0.2$ & $67.8 \pm 0.2$ & $75.6 \pm 0.2$ & $83.8 \pm 1.2$ & $54.3 \pm 0.5$ & $75.1 \pm 0.8$ & $80.7 \pm 5.4$ & $96.4 \pm 0.2$ \\
\hline Total USFA ${ }^{5)}$ & $17.4 \pm 0.2$ & $32.2 \pm 0.2$ & $24.4 \pm 0.2$ & $16.2 \pm 1.2$ & $45.7 \pm 0.5$ & $24.9 \pm 0.8$ & $19.6 \pm 5.4$ & $3.6 \pm 0.2$ \\
\hline
\end{tabular}

${ }^{1)}$ Not detected.

${ }^{2)}$ Mean \pm SD $(\mathrm{n}=2)$.

${ }^{3)}$ Means in the same row with different letters are significantly different at $\mathrm{p}<0.05$ level.

${ }^{4)}$ Total saturated fatty acids.

${ }^{5)}$ Total unsaturated fatty acids.

\section{감사의 글}

본 연구는 2017년도 대구대학교 학술연구비 지원에 의 해 이루어진 결과로 이에 감사드립니다.

\section{Conflict of interests}

The authors declare no potential conflict of interest.

\section{ORCID}

So-Ra Sim https://orcid.org/0000-0003-4062-4953 Jeung Hee Lee https://orcid.org/0000-0002-4224-771X 


\section{References}

AT Food Information Statistics System. https://www.atfis.or. $\mathrm{kr} /$ article/M001010000/view.do?articleId=3245 （acessed July 2019)

Choi MJ, Shin KS. Studies on physical and sensory properties of premium vanilla ice cream distributed in Korean market. Korean J Food Sci Anim Resour, 34, 757-762 (2014)

Clarke C. The Science of Ice Cream. PSC Publishing Co., Cambridge, UK, p 52-54 (2015)

Duan BB, Shin JA, Lee KT. The contents of $\beta$-carotene and cholesterol in selected types of agricultural and processed foods in Korea. Korean J Agric Sci, 46, 315-322 (2019)

Goff HD, Hartel RW. Composition and Formulations. In: Ice Cream, 7th Ed, Springer Publishing Co, Boston, MA, USA, p 19-44 (2013)

Goff HD. Ice cream and frozen desserts. In: Ullmann's Encyclopedia of Industrial Chemistry, Wiley-VCH Verlag GmbH \& Co, Weinheim, Germany, p 1-15 (2016)

Han SH. Ice Cream. Yuhan Publishing Co, Seoul, Korea, p 59-61 (2005)

Han EM, Kim SH, Kwak HS. Cholesterol removal of milk and dairy products using $\beta$-cyclodextrin. Korean J Food Sci Ani Resour, 26, 540-547 (2006)

Han GD. Food Processing and Science of Animal Resources. Seoghwadang Publishing Co., Seoul, Korea, p 26-27 (2017)

Jeong JR, Seo KS, Lee SG, Jo EJ, Na MS, Jeong JH, Oh SI, Son MO. Trans fatty acid content in commercial processed food in Jeon-buk area. Korean J Nutr, 42, 291-299 (2009)

KSIC (Korean Standard Industrial Classification). code 5619 4. https://kssc.kostat.go.kr:8443/ksscNew_web/link.do?g ubun=001. (accessed July 2017)

Keszycka MM, Runowska GC, Lipinska P, Wojtowski J. Fatty acid profile of milk - A review. Bull Vet Inst Pulawy, 57, 135-139 (2013)

Kilara A, Chandan RC. Ice cream and frozen desserts. In: Handbook of Food Products Manufacturing, Hui YH (Editor), Wiley Publishing Co., Hoboken, NJ, USA, p
593-633 (2007)

Kolk K, Linnik I, Pallin R, Pussa T. The content of cholesterol of estonian yoghurt and ice cream. Estonian Univ Life Sci, 1, 20-24 (2007)

Kuhnt K, Baehr M, Rohrer C, Jahreis G. Trans fatty acid isomers and the trans-9/trans-11 index in fat containing foods. Eur J Lipid Sci Technol, 113, 1281-1292 (2011)

Mansson HL. Fatty acids in bovine milk fat. Food Nutr Res, 52, 1-3 (2008)

MFDS (Ministry of Food and Drug Safety). http://www.food safetykorea.go.kr/foodcode/03_02.jsp?idx=23 (accessed April 2020)

NAS (National Institute of Agricultural Sciences). https://kor eanfood.rda.go.kr:2360/kfi/fct/fctIntro/list?menuId=PS03 562 (accessed December 2016)

Oh HI, Shin TS, Chang EJ. Determination of cholesterol in milk and dairy products by high-performance liquid chromatography. Asian-Australas J Anim Sci, 14, 14651469 (2001)

Ohlsson L. Dairy products and plasma cholesterol levels. Food Nutr Res, 54, 1-9 (2010)

Parodi PW. Milk fat in human nutrition. Aust J airy Technol, 59, 3-59 (2004)

Posati LP, Orr ML. Composition of foods: dairy and egg products, raw, processed and prepared. Agricultural HB 8-1, ARS, USDA, p 15-17, p 63-68, p 75-80 (1976)

Shin MK, Oh HH, Hwang KT. Contents and fatty acid compositions in fats extracted from ice creams and ice cream-related products. J Korean Soc Food Sci Nutr, 35, 721-728 (2006)

Smith KW. Specialty oils and fats in ice cream. In: Specialty Oils and Fats in Food and Nutrition, Talbot G (Editor), Woodhead Publishing Co, Philadelphia, PA, USA, p 271-284 (2015)

Underdown J, Quail PJ, Smith KW. Saturated fat reduction in ice cream. In: Reducing Saturated Fats in Foods, Talbot G (Editor), Woodhead Publishing Co, Philadelphia, PA, USA, p 350-369 (2011)

Warren MM, Hartel RW. Structural, compositional, and sensorial properties of United States commercial ice cream products. J Food Sci, 79, E2005-E2013 (2014) 